\title{
PENERAPAN METODE PROMETHEE UNTUK PENDUKUNG KEPUTUSAN PEMILIHAN SMARTPHONE TERBAIK
}

\author{
${ }^{1}$ Tri Juninda, ${ }^{2}$ Elvia Andri, ${ }^{3}$ Ulya Khairunnisa, ${ }^{4}$ Novi Kurniawati, ${ }^{5}$ Mustakim \\ 1,2,3,4,5 Program Studi Sistem Informasi, Fakultas Sains dan Teknologi UIN UIN Sultan Syarif Kasim Riau \\ 1,2,3,5 Puzzle Research Data Tecnology, Fakultas Sains dan Teknologi UIN Sultan Syarif Kasim Riau \\ J1. HR Soebrantas KM.18 Panam Pekanbaru - Riau \\ Email: ${ }^{1} 11653200095 @$ students.uin-suska.ac.id, ${ }^{2} 11653200497 @$ students.uin-suska.ac.id, \\ 311653201346@students.uin-suska.ac.id, ${ }^{4} 11653200203 @$ students.uin-suska.ac.id, ${ }^{5}$ mustakim@uin-suska.ac.id
}

\begin{abstract}
ABSTRAK
Perkembangan dan penjualan smartphone yang semakin meningkat membuat banyak vendor smartphone bersaing untuk menawarkan berbagai macam fitur pada smartphone yang mereka pasarkan, sehingga masyarakat sering dihadapkan pada permasalahan-permasalahan yaitu kesulitan dalam menentukan smartphone yang akan dibeli. Hal ini disebabkan karena banyaknya smartphone yang menawarkan fitu-fitur canggih dengan harga yang murah. Pemilihan smartphone ini dapat ditentukan berdasarkan kriteria yang telah dipilih diantaranya harga, ukuran layar, Random Acces Momory (RAM), Read Only Memory (ROM), processor, kamera, dan kapasitas baterai. Sebagai gambaran dan rekomendasi kepada masyarakat dalam memilih smartphone yang tepat digunakanlah metode PROMETHEE. Metode ini mampu dijadikan sebagai alat bantu dalam pengambilan keputusan. Metode PROMETHEE bekerja dengan melakukan penentuan atau pengurutan dalam suatu analisis multikriteria. Hasil dari penelitian ini memberikan suatu rekomendasi kepada masyarakat dalam melakukan pemilihan smartphone yang sesuai dengan keinginan dan kebutuhan berdasarkan kriteria yang telah ditentukan. Berdasarkan hasil penelitian, direkomendasikan bahwa beberapa alternatif peringkat tertinggi adalah Oppo F7, Vivo V11, dan Oppo F9 sebagi bahan pertimbangan dalam pembelian smartphone.
\end{abstract}

Kata kunci: Alternatif, Kriteria, Pendukung Keputusan, PROMETHEE, Smarthpone.

\section{A. PENDAHULUAN}

Perkembangan teknologi informasi yang semakin pesat membuat kebutuhan masyarakat dalam hal tersebut semakin meningkat. Salah satu dari perkembangan teknologi tersebut adalah smartphone. Smartphone tidak lagi menjadi barang mewah seperti sebelumnya dimana smartphone merupakan suatu benda yang hampir tidak bisa dipisahkan dalam kehidupan dan aktivitas seharihari, kehadiran smartphone dapat mempercepat dan mempermudah berbagai kegiatan mulai dari untuk berkomunikasi, mencari informasi di internet, sosial media, hingga berbisnis. Kebutuhan yang tinggi terhadap smartphone membuat vendorvendor smartphone berlomba-lomba dalam meluncurkan produk mereka, dengan melihat trend di masyarakat vendor smartphone membuat produknya sebaik mungkin sehingga dapat bersaing dan banyak diminati oleh masyarakat.

Terdapat banyak fitur yang ditawarkan sebagai bahan untuk menarik minat pembeli mulai dari processor, ukuran layar, kamera, RAM, ROM, kapasitas batrai, sistem operasi, dan masih banyak fitur-fitur lainnya. Beberapa penelitian terkait pemilihan smartphone menurut Binarso (2014) menggunakan metode Simple Adaptive Waighting dalam memilih smartphone dengan kriteria kecepatan processor, kapasitas kamera, kapasitas RAM, kapasitas penyimpanan internal, harga, kapasitas baterai, core processor, proteksi layar, operating system, dan konektifitas [1]. Menurut
Harsiti dan Aprianti (2017) juga menggunakan metode Simple Adaptive Waighiting dengan kriteria harga, RAM, memory internal, kamera, dan ukuran layar [2]. Penelitian terkait lainnya tentang pemilihian gedget android menggunakan metode PROMETHEE menurut Gunawan dan Astuti (2013) menggunakan 11 kriteria yaitu kecepatan processor, kapasitas RAM, kapasitas internal, harga, kapasitas baterai, kamera primer, core processor, proteksi layar, operating system, jaringan 4G/LTE, dan NFC. Pada penelitian tersebut didapatkan hasil urutan netflow pertama HTC ONE+ sebesar 0.539393, urutan kedua yaitu Samsung I9300 Galaxy S III sebesar 0.203031 dan urutan ketiga yaitu Samsung Galaxy Note 10.1 N8000 sebesar -0.742424, yang mana urutan tersebut merupakan hasil perangkingan sistem yang dapat dijadikan rekomendasi untuk pembeli [3].

Kurangnya informasi masyarakat tentang fitur-fitur yang tersedia pada smartphone saat ini membuat masyarakat kebingungan saat akan membeli smartphone yang cocok untuk kebutuhan mereka. Banyaknya aspek yang harus dipertimbangkan menjadi kendala masyarakat dalam menentukan smartphone yang akan mereka beli mulai dari harga hingga spesifikasi yang tersedia pada berbagai macam merek dan tipe smartphone yang ada.

Metode Preference Ranking Organization Method for Enrichment Evaluation (PROMETHEE) merupakan suatu metode 
penentuan urutan ataupun prioritas dalam suatu analisis multikriteria yang memberikan cara sederhana dan fleksibel kepada pengguna untuk menganalisis masalah multikriteria [4]. Metode PROMETHEE mempunyai kelebihan dalam proses pemeringkatan alternatif menggunakan fungsi preferensi dan bobot yang berbeda-beda [5].

PROMETHEE adalah suatu metode Multi Criteria Decision Making (MCDM) atau dapat melakukan pengurutan atau penentuan dalam analisis multikriteria. Metode PROMETHEE memiliki konsep yang sederhana dan efisien dalam menyelesaikan masalah multikriteria [6]. MCDM adalah studi tentang metode dan prosedur dimana keprihatinan tentang berbagai kriteria yang saling bertentangan yang dimasukan kedalam proses perencanaan manajemen sebagaimana didefinisikan oleh International Society on Multiple Criteria Decision Making [7]. Metode MCDM dapat membantu dalam memilih alternatif terbaik dimana terdapat banyak kriteria dengan menganalisis ruang lingkup dari kriteria dan bobot untuk kriteria tersebut [8].

Berdasarkan permasalahan tersebut digunakanlah suatu metode untuk membantu dalam memberikan keputusan kepada masyarakat dalam memilih smartphone yang cocok serta sesuai dengan harga dan spesifikasinya menggunakan metode PROMETHEE.

\section{B. METODOLOGI PENELITIAN}

Metode penelitian ini bertujuan untuk mendapatkan rekomendasi smartphone dengan fitur dan harga terbaik agar nantinya dapat menjadi bahan pertimbangan dalam menentukan pembelian smartphone dengan kualitas yang baik pula. Metode penelitian ditunjukkan pada gambar 1 .

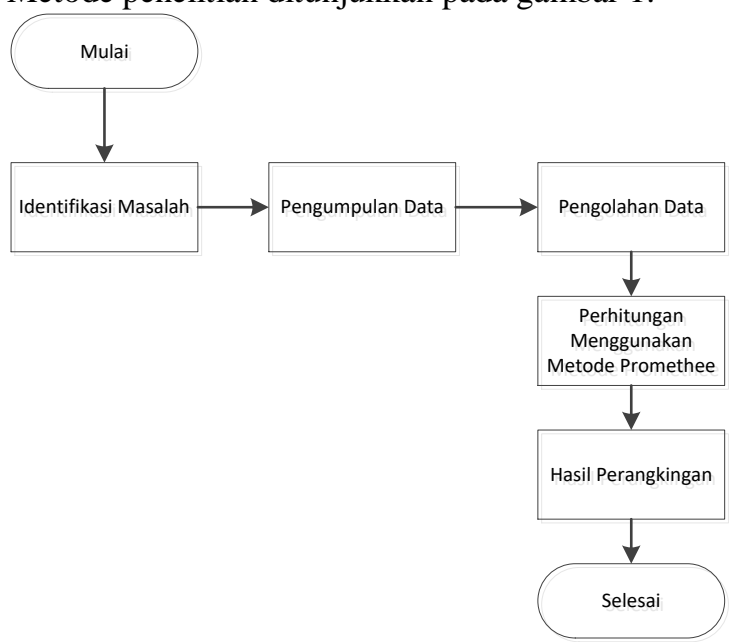

Gambar 1. Metode Penelitian

Metode penelitian yang dilakukan yaitu dimulai dari identifikasi masalah, kemudian melakukan pengumpulan data smartphone serta melakukan wawancara kepada pembeli. Selanjutnya melakukan pengolahan data dengan menggunakan Microsoft Excel dan menganalisa hasil dari wawancara. Setelah melakukan pengolahan data lalu melakukan perhitungan menggunakan metode PROMETHEE hingga didapatkan hasil perangkingan daftar smartphone terbaik.

\section{B.1. PROMETHEE}

Preference Ranking Organization Method for Enrichment Evalution (PROMETHEE) adalah suatu metode untuk menentukan urutan (prioritas) dalam analisis multikriteria. Metode PROMETHEE merupakan suatu metode yang sederhana dan efisien, tetapi juga mudah diimplementasikan daripada metode lain untuk menuntaskan masalah multikriteria [9] [6]. Pemilihan yang bersifat kuantitatif dan kualitatif dapat diakomodir dengan metode PROMETHEE ini [10]. Dugaan dari dominasi kriteria yang digunakan dalam PROMETHEE adalah penggunaan nilai dalam hubungan outranking [11]. Metode PROMETHEE juga sering digunakan dalam beberapa aspek di kehidupan sehari-hari seperti bidang pendidikan, pertanian, pemerintahan, dan olahraga [12]. Langkah-langkah perhitungan dengan metode PROMETHEE ditunjukkan pada gambar 2.

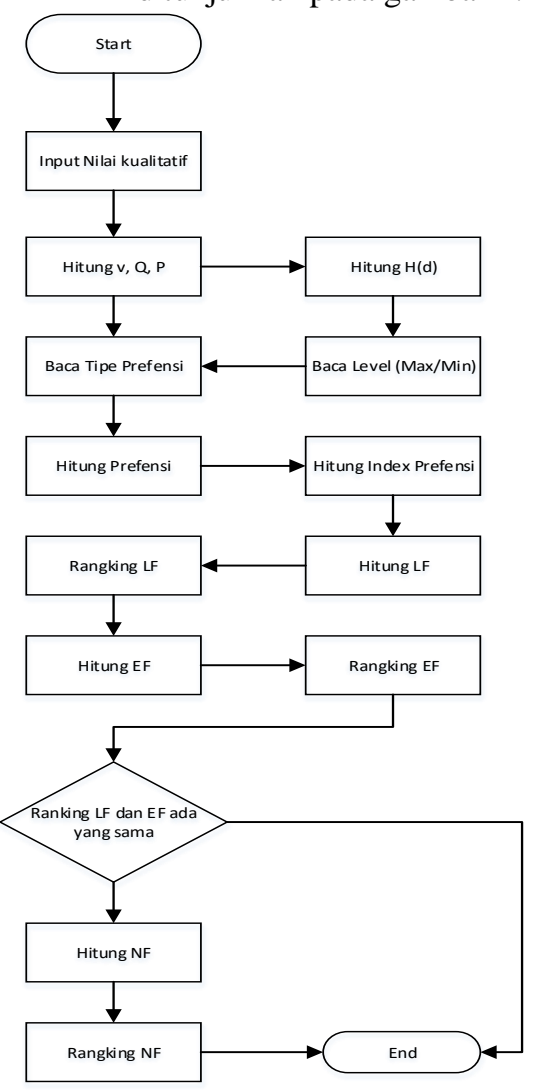

Gambar 2. Flowchart Metode PROMETHEE

Dalam metode PROMETHEE terdapat dua macam perangkingan berdasarkan pada hasil perhitungan, yaitu: 
1. Perangkingan parsial, yaitu perangkingan berdasarkan pada nilai Entering flow dan Leaving flow.

2. Perangkingan lengkap, yaitu perangkingan berdasarkan pada nilai Net flow.

Dalam metode PROMETHEE terdapat enam bentuk fungsi preferensi kriteria, dimana hal tersebut digunkan untuk memberikan gambaran yang lebih baik terhadap area yang tidak sama. Enam tipe preferensi tersebut yaitu [6] [13]:

a. Kriteria Usual

$$
H(d)=\left\{\begin{array}{l}
0 \text { jikad } \leq 0 \\
1 \text { jika } d>0
\end{array}\right.
$$

$\mathrm{H}(d)=$ fungsi selisih nilai kriteria antara alternatif

$d=$ selisih nilai kriteria $\{d=f(a)-f(b)\}$

b. Kriteria Quasi (Quasi Criterion / U-Shape)

$$
H(d)=\left\{\begin{array}{l}
0 \text { jikad } \leq q \\
1 \text { jika } d>q
\end{array}\right.
$$

$\mathrm{H}(d)=$ fungsi selisih nilai kriteria antar alternatif

$d=$ selisih nilai kriteria $\{d=f(a)-f(b)\}$

$q=$ harus merupakan nilai tetap

c. Kriteria Linier (Linier Criterion / -Shape)

$$
H(d)=\left\{\begin{array}{c}
0 \text { jika } d \leq 0 \\
\frac{d}{p} \text { jika } 0 \leq d \leq p \\
1 \text { jika } d>p
\end{array}\right.
$$

$\mathrm{H}(d)=$ fungsi selisih kriteria antar alternatif $d=$ selisih nilai kriteria $\{d=f(a)-f(b)\}$ $p=$ nilai kecenderungan atas

d. Kriteria Level (Level Criterion)

$$
H(d)=\left\{\begin{array}{c}
0 \text { jika } d \leq q \\
0,5 \text { jika } q<d \leq p \\
1 \text { jika } d>p
\end{array}\right.
$$

$\mathrm{H}(d)=$ fungsi sleisih kriteria antar alternatif $d=$ selisih nilai kriteria $\{d=f(a)-f(b)\}$

$p=$ nilai kecenderungan atas

$q=$ harus merupakan nilai tetap

e. Kriteria dengan Preferensi Linier dan Area yang Tidak Berbeda

$$
H(d)=\left\{\begin{array}{c}
0 \text { jika } d \leq q \\
\frac{d-q}{p-q} \text { jika } q \leq d \leq p \\
1 \text { jika } d>p
\end{array}\right.
$$

$\mathrm{H}(d)=$ fungsi sleisih kriteria antar alternatif $d=$ selisih nilai kriteria $\{d=f(a)-f(b)\}$ $p=$ nilai kecenderungan atas $q=$ harus merupakan nilai tetap f. Kriteria Gaussian (Gaussian Criterion)

$$
H(d)=\left\{\begin{array}{c}
0 \text { jikad } \leq 0 \\
1-e-\frac{d^{2}}{2 a^{2}} \text { jika } d>0
\end{array}\right.
$$

$\mathrm{H}(d)=$ fungsi sleisih kriteria antar alternatif $d=$ selisih nilai kriteria $\{d=f(a)-f(b)\}$

Dalam metode PROMETHEE terdapat tiga jenis perangkingan, yaitu [6] [14]:

1. Menghitung Leaving Flow

$$
\theta^{+}(a)=\frac{1}{n-1} \sum_{x \varepsilon A} \varphi(a, x)
$$

Keterangan:

$\varphi(a, x)=$ preferensi nilai a lebih baik daripada nilai $\mathrm{x}$

$n=$ banyaknya jumlah alternatif

$\sum x \varepsilon A=$ nilai alternatif dari tabel preferensi dijumlahkan secara horizontal

2. Menghitung Entering Flow

$$
\theta^{-}(a)=\frac{1}{n-1} \sum_{x \varepsilon A} \varphi(a, x)
$$

Keterangan:

$\varphi(a, x)=$ preferensi nilai a lebih baik daripada nilai $\mathrm{x}$

$n=$ banyaknya jumlah alternatif

$\sum x \varepsilon A=$ nilai alternatif dari tabel preferensi dijumlahkan secara vertikal

3. Menghitung Net Flow

$$
\theta(a)=\theta^{+}(a)-\theta^{-}(a)
$$

Keterangan:

$\theta^{+}(a)=$ persamaan rumus leaving flow (Promethee I)

$\theta^{-}(a)=$ persamaan rumus entering flow (Promethee I)

$\theta(a)=$ persamaan rumus net flow (Promethee II)

\section{HASIL DAN ANALISIS}

\section{C.1. Analisa Sistem yang Sedang Berjalan}

Untuk menentukan alternatif dan kriteria, peneliti melakukan survei data langsung ke konterkonter pembelian smartphone untuk mendapatkan data smartphone yang paling diminati dan fiturfitur smartphone yang diperhitungkan dalam pembeliannya. Dalam penelitian ini ada dua puluh alternatif dan delapan kriteria yang dapat digunakan. Kriteria dan jenis kriteria ditunjukkan pada tabel 1 .

Tabel.1 Kriteria dan Jenis Kriteria

\begin{tabular}{lcc}
\hline \multicolumn{1}{c}{ Kriteria } & Ket. Kriteria & Jenis \\
\hline Harga & K1 & Cost \\
Layar & K2 & Benefit \\
RAM & K3 & Benefit \\
ROM & K4 & Benefit \\
Processor & K5 & Benefit \\
\hline
\end{tabular}




\begin{tabular}{lcc}
\hline \multicolumn{1}{c}{ Kriteria } & Ket. Kriteria & Jenis \\
\hline Kamera & K6 & Benefit \\
Belakang & & \\
Kamera Depan & K7 & Benefit \\
Baterai & K8 & Benefit \\
\hline
\end{tabular}

Sebagai bahan pengumpulan data, penelitian ini mengambil 20 jenis smartphone yang sering diperhitungkan oleh masyarakat pada umumnya, ke 20 alternatif tersebut ditunjukkan pada tabel 2.

Tabel.2 Rating Kecocokan dari Setiap Kriteria

\begin{tabular}{lccccccccc}
\hline \multirow{2}{*}{ Alternatif } & \multirow{2}{*}{ Ket. Alternatif } & \multicolumn{7}{c}{ Kriteria } \\
\cline { 3 - 9 } & & $\mathrm{K} 1$ & $\mathrm{~K} 2$ & $\mathrm{~K} 3$ & $\mathrm{~K} 4$ & $\mathrm{~K} 5$ & $\mathrm{~K} 6$ & $\mathrm{~K} 7$ & $\mathrm{~K} 8$ \\
\hline Oppo F9 & $\mathrm{B}$ & 3 & 5 & 5 & 3 & 5 & 2 & 5 & 3 \\
Oppo A3s & $\mathrm{C}$ & 4 & 3 & 2 & 5 & 2 & 2 & 5 \\
Oppo F7 & $\mathrm{C}$ & 3 & 5 & 5 & 4 & 5 & 5 & 5 & 3 \\
Oppo F7 Youth & $\mathrm{D}$ & 3 & 4 & 4 & 3 & 5 & 2 & 2 & 3 \\
Oppo A83 & $\mathrm{E}$ & 4 & 3 & 3 & 2 & 5 & 2 & 2 & 3 \\
Vivo V11 Pro & $\mathrm{F}$ & 3 & 5 & 5 & 3 & 5 & 1 & 5 & 3 \\
Vivo V11 & $\mathrm{G}$ & 3 & 5 & 5 & 3 & 5 & 2 & 5 & 4 \\
Vivo V9 & $\mathrm{H}$ & 3 & 5 & 4 & 3 & 5 & 2 & 4 & 3 \\
Vivo Y81 & $\mathrm{I}$ & 4 & 5 & 3 & 2 & 5 & 2 & 1 & 3 \\
Vivo Y71 & $\mathrm{J}$ & 4 & 4 & 3 & 2 & 5 & 2 & 1 & 3 \\
Samsung Galaxy A8 Star & $\mathrm{K}$ & 1 & 5 & 4 & 3 & 5 & 4 & 4 & 3 \\
Samsung Galaxy A7 & $\mathrm{L}$ & 3 & 4 & 4 & 3 & 5 & 4 & 4 & 3 \\
Samsung Galaxy Note & $\mathrm{M}$ & 1 & 5 & 5 & 4 & 5 & 1 & 2 & 4 \\
Samsung Galaxy J6+ & $\mathrm{N}$ & 4 & 4 & 3 & 2 & 3 & 2 & 2 & 3 \\
Samsung Galaxy J4+ & $\mathrm{O}$ & 4 & 4 & 2 & 2 & 3 & 2 & 1 & 3 \\
Xiaomi 6A & $\mathrm{P}$ & 4 & 3 & 3 & 2 & 3 & 2 & 1 & 2 \\
Xiaomi 5A & $\mathrm{Q}$ & 4 & 1 & 3 & 2 & 3 & 2 & 1 & 2 \\
Xiaomi Redmi 5 & $\mathrm{R}$ & 4 & 3 & 2 & 1 & 5 & 1 & 1 & 3 \\
Xiaomi Note 5 & $\mathrm{S}$ & 4 & 4 & 4 & 3 & 5 & 1 & 3 & 4 \\
Xiaomi Note 5A & $\mathrm{T}$ & 4 & 3 & 4 & 3 & 5 & 2 & 1 & 3 \\
\hline
\end{tabular}

Tabel 2 menunjukkan rating kecocokan dari alternatif yang ada pada setiap keriteria yang telah ditentukan. Setiap nilai yang diberikan pada setiap alternatif keriteria merupakan nilai kecocokan dimana nilai yang terbesar merupakan nilai terbaik.
Setelah didapatkan rating kecocokan maka dilakukan perhitungan menggunakan persamaan 1 . Selanjutnya lakukan perhitungan indeks preferensi multi kriteria seperti ditunjukkan pada tabel 3 .

Tabel.3 Indeks Preferensi Multi Kriteria

\begin{tabular}{ccccccccc}
\hline & $\mathrm{A}$ & $\mathrm{B}$ & $\mathrm{C}$ & $\mathrm{D}$ & $\mathrm{E}$ & $\ldots$ & $\mathrm{T}$ & \\
\hline $\mathrm{A}$ & 0.000 & 0.500 & 0.000 & 0.375 & 0.500 & $\ldots$ & 0.375 & 8.250 \\
$\mathrm{~B}$ & 0.250 & 0.000 & 0.250 & 0.250 & 0.250 & $\ldots$ & 0.625 & 6.625 \\
$\mathrm{C}$ & 0.250 & 0.625 & 0.000 & 0.625 & 0.625 & $\ldots$ & 0.625 & 11.125 \\
$\mathrm{D}$ & 0.000 & 0.250 & 0.000 & 0.000 & 0.375 & $\ldots$ & 0.250 & 5.250 \\
$\mathrm{E}$ & 0.125 & 0.000 & 0.125 & 0.125 & 0.000 & $\ldots$ & 0.125 & 3.750 \\
$\mathrm{~F}$ & 0.000 & 0.500 & 0.000 & 0.375 & 0.500 & $\ldots$ & 0.375 & 7.500 \\
$\mathrm{G}$ & 0.125 & 0.500 & 0.125 & 0.500 & 0.625 & $\ldots$ & 0.500 & 9.750 \\
$\mathrm{H}$ & 0.000 & 0.500 & 0.000 & 0.250 & 0.500 & $\ldots$ & 0.250 & 6.875 \\
$\mathrm{I}$ & 0.125 & 0.125 & 0.125 & 0.250 & 0.125 & $\ldots$ & 0.125 & 4.125 \\
$\mathrm{~J}$ & 0.125 & 0.000 & 0.125 & 0.125 & 0.125 & $\ldots$ & 0.125 & 3.250 \\
$\mathrm{~K}$ & 0.125 & 0.625 & 0.000 & 0.375 & 0.625 & $\ldots$ & 0.375 & 8.125 \\
$\mathrm{~L}$ & 0.125 & 0.500 & 0.000 & 0.250 & 0.625 & $\ldots$ & 0.375 & 7.500 \\
$\mathrm{M}$ & 0.250 & 0.375 & 0.125 & 0.500 & 0.500 & $\ldots$ & 0.625 & 9.000 \\
$\mathrm{~N}$ & 0.125 & 0.000 & 0.125 & 0.125 & 0.125 & $\ldots$ & 0.25 & 3.625 \\
$\mathrm{O}$ & 0.125 & 0.000 & 0.125 & 0.125 & 0.125 & $\ldots$ & 0.125 & 2.625 \\
$\mathrm{P}$ & 0.125 & 0.000 & 0.125 & 0.125 & 0.000 & $\ldots$ & 0.000 & 2.125 \\
$\mathrm{Q}$ & 0.125 & 0.000 & 0.125 & 0.125 & 0.000 & $\ldots$ & 0.000 & 2.125 \\
$\mathrm{R}$ & 0.125 & 0.000 & 0.125 & 0.125 & 0.000 & $\ldots$ & 0.000 & 2.000 \\
$\mathrm{~S}$ & 0.250 & 0.375 & 0.250 & 0.375 & 0.625 & $\ldots$ & 0.375 & 7.125 \\
$\mathrm{~T}$ & 0.125 & 0.25 & 0.125 & 0.125 & 0.250 & $\ldots$ & 0.000 & 4.750 \\
& 2.500 & 5.125 & 1.875 & 5.125 & 6.500 & $\ldots$ & 5.500 & \\
\hline
\end{tabular}


Jurnal Ilmiah Rekayasa dan Manajemen Sistem Informasi, Vol. 5, No. 2, Agustus 2019, Hal. 224-229 e-ISSN 2502-8995 p-ISSN 2460-8181

Tabel 3 menunjukkan indeks preferensi multikriteria yang mana hasil ini ditentukan berdasarkan rata-rata bobot dari fungsi preferensi.

Tabel.4 Nilai Leaving Flow, Entering Flow, dan

\begin{tabular}{cccc}
\multicolumn{4}{c}{ Net Flow } \\
\hline Alternatif & $\begin{array}{c}\text { Leaving } \\
\text { Flow }\end{array}$ & $\begin{array}{c}\text { Entering } \\
\text { Flow }\end{array}$ & Net Flow \\
\hline A & 0.4342 & 0.1315 & 0.3026 \\
B & 0.3486 & 0.2697 & 0.0789 \\
C & 0.5855 & 0.0986 & 0.4868 \\
D & 0.2763 & 0.2697 & 0.0065 \\
E & 0.1973 & 0.3421 & -0.1447 \\
F & 0.3947 & 0.2039 & 0.1907 \\
G & 0.5131 & 0.1118 & 0.4013 \\
H & 0.3618 & 0.1842 & 0.1776 \\
I & 0.2171 & 0.2565 & -0.0394 \\
J & 0.1710 & 0.3092 & -0.1381 \\
K & 0.4276 & 0.2302 & 0.1973 \\
L & 0.3947 & 0.2434 & 0.1513 \\
M & 0.4736 & 0.2828 & 0.1907 \\
N & 0.1907 & 0.4013 & -0.2105 \\
O & 0.1381 & 0.4802 & -0.3421 \\
P & 0.1118 & 0.5657 & -0.4539 \\
Q & 0.1118 & 0.5986 & -0.4868 \\
R & 0.1052 & 0.5526 & -0.4473 \\
S & 0.3750 & 0.2565 & 0.1184 \\
T & 0.2500 & 0.2894 & -0.0394 \\
\hline
\end{tabular}

Tabel 4 merupakan perhitungan dari Leaving Flow, Entering Flow, dan Net Flow yang didapatkan berdasarkan persamaan 7, 8, dan 9 . Perangkingan hasil akhir ditentukan berdasarkan nilai Net Flow, yang ditunjukkan pada gambar 3.

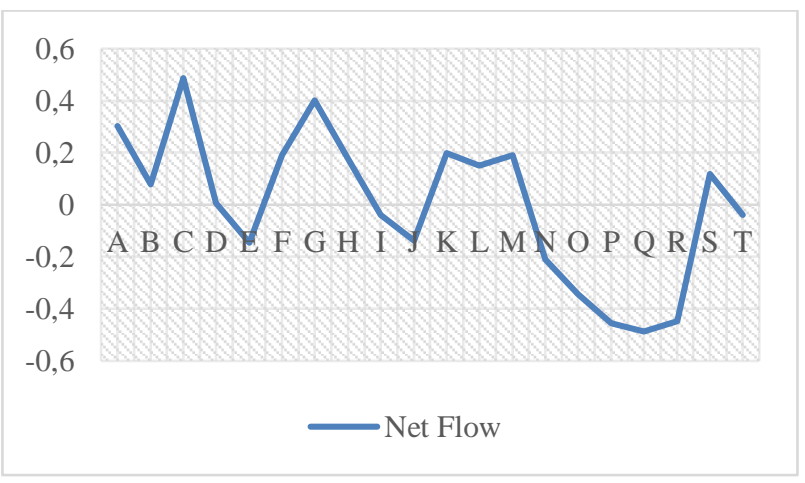

Gambar 3. Grafik nilai Net Flow

Berdasarkan grafik tersebut didapatkan hasil akhir perangkingan PROMETHEE yang ditunjukkan pada tabel 5 .

Tabel.5 Hasil Perangkingan Promethee

\begin{tabular}{cc}
\hline Ranking & Alternatif \\
\hline 1 & Oppo F7 \\
2 & Vivo V11 \\
3 & Oppo F9 \\
4 & Samsung Galaxy A8 Star \\
5 & Vivo V11 Pro \\
\hline
\end{tabular}

\begin{tabular}{cc}
\hline Ranking & Alternatif \\
\hline 6 & Samsung Galaxy Note 9 \\
7 & Vivo V9 \\
8 & Samsung Galaxy A7 \\
9 & Xiaomi Note 5 \\
10 & Oppo A3s \\
11 & Oppo F7 Youth \\
12 & Vivo Y81 \\
13 & Xiaomi Note 5A \\
14 & Vivo Y71 \\
15 & Oppo A83 \\
16 & Samsung Galaxy J6+ \\
17 & Samsung Galaxy J4+ \\
18 & Xiaomi Redmi 5 \\
19 & Xiaomi 6A \\
20 & Xiaomi 5A \\
\hline
\end{tabular}

Tabel 5 merupakan hasil perangkingan dari metode PROMETHEE. Ranking tersebut didapatkan berdasarkan pengurutan nilai Net Flow tertinggi hingga terendah. Dimana Oppo F7 mendapatkan rangking pertama dengan nilai net flow 0.4868 sedangkan Vivo V11 menempati peringkat kedua dengan nilai net flow 0.4013 dan Oppo F9 sebagai peringkat ketiga dengan nilai net flow 0.3026 .

\section{KESIMPULAN}

Berdasarkan penelitian yang telah dilakukan dapat diambil kesimpulan bahwa pemilihan smartphone terbaik menggunakan metode PROMETHEE dapat menangani masalah untuk menentukan urutan (prioritas) dalam analisis multikriteria. Berdasarkan hasil penelitian didapatkan beberapa alternatif perangkingan dengan nilai tertinggi diantaranya yaitu Oppo F7, Vivo V11 dan Oppo F9 yang dapat direkomendasikan sebagai bahan pertimbangan dalam pembelian smartphone dengan spesifikasi terbaik saat ini.

Penelitian ini memberikan hasil yang lebih selektif dalam membuat ranking, karena membandingkan setiap alternatif dengan alternatif yang lain dari tingkat tertinggi hingga terendah sehingga dapat memberikan kesempatan kepada konsumen untuk dapat melihat kelebihan dan kekurangan yang lebih spesifik pada suatu smartphone dalam kriteria tertentu. Namun, hasil perangkingan dapat berubah tergantung dengan prioritas fitur smartphone yang dianggap lebih penting oleh pihak konsumen.

Penelitian ini dilakukan berdasarkan survey dari beberapa konter penjualan smartphone yang ada di Pekanbaru. Metode PROMETHEE ini dapat diimplementasikan untuk menghasilkan rekomendasi dalam pemilihan smartphone terbaik berdasarkan alternatif dan kriteria yang telah ditentukan. 


\section{REFERENSI}

[1] A. Binarso F, "Sistem Pendukung Keputusan Pemilihan Gedget Smartphone Menggunakan Metode Simple Additive Weighting," Skripsi Fakultas Ilmu Komputer Universitas Dian Nuswantoro, Semarang, 2014.

[2] Harsiti and H. Aprianti, "Sistem Pendukung Keputusan Pemilihan Smartphone dengan Menerapkan Metode Simple Additive Weighting (SAW)," Jurnal Sistem Informasi, vol. 4, pp. 19-24, 2017.

[3] Gunawan and S. Astuti, "Sistem Pendukung Keputusan Pemilihan Geget Android Menggunakan Metode Promethee," Jurnal Teknologi Informasi, vol. 12, no. 2, pp. 104116, 2013.

[4] J. D. C. Little, "Models and Managers: The Concept of a Decision Calculus," Management Science, vol. 16, no. 8, 1970.

[5] P. Mursanto and W. Sari, "Defining Relative Qualities of Object Oriented Design Implementation Using AHP and Promethee," in Proceedings of The International Symposium on The Analytic Hierarchy Process, 2011.

[6] T. Imandasari, A. Wanto and A. P. Windarto, "Analisis Pengambilan Keputusan dalam Menentukan Mahasiswa PKL Menggunakan Metode Promethee," Jurnal Riset Komputer (JURIKOM), vol. 5, no. 3, pp. 234-239, 2018.

[7] M. A. Alias, S. Z. M. Hashim and S. Samsudin, "Multi Criteria Decison Making and Its Applications: A Literature Review," Jurnal Teknologi Maklumat, vol. 20, no. 2, pp. 129-152, 2008.

[8] P. Murali, V. D. Reddy and A. N. Phaneendra, "Supplier Selection by Using Multi Criteria Decision Making Methods," International Journal of Engineering Research and General
Science, vol. 2, no. 6, pp. 533-539, 2014.

[9] M. Doumpos and C. Zopounidis, "A Multicriteria Decision Support System for Bank Rating," Decision Support System and Electronic Commerce, vol. 50, no. 1, pp. 5563, 2010.

[10] H. Budiharjo, H. Sofyan and Suparja, "Perencanaan Sistem Pendukung Pengambilan Keputusan Penerimaan Taruna dengan Metode Promethee (Studi Kasus Seleksi Taruna Akmil)," Seminar Nasional Informatika (SEMNASIF), vol. 1, no. 1, pp. 147-155, 2015.

[11] F. H. Prabowo, "Penerapan Metode Promethee dalam Menentukan Prioritas Pinjaman Kredit Pemilikan Rumah (KPRIB) kepada Nasabah Debitur," Skripsi Jurusan Sistem Informasi Sekolah Tinggi Manajemen Informatika \& Teknik Komputer Surabaya, Surabaya, 2011.

[12] M. Behzadian, R. Kazemzadeh, A. Albadvi and M. Aghdasi, "PROMETHEE: A Comprehensive Literature Review on Methodologies and Applications," European Journal of Operational Research, vol. 200, no. 1, pp. 198-215, 2010.

[13] C. Onggo and F. Noviyanto, "Sistem Pendukung Keputusan untuk Pemilihan Lokasi Pembukaan Cabang Usaha Variasi Mobil dengan Metode Promethee," Jurnal Sarjana Teknik Informatika, vol. 1, no. 1, pp. 140-149, 2013.

[14] M. H. Bagaskara, M. T. Furqon and Sutrisno, "Sistem Pendukung Keputusan Penentuan Prioritas Pemeliharaan Jalan Menggunakan PROMETHEE II (Studi Kasus: Dinas Pekerjaan Umum dan Penataan Ruang Kabupaten Ponorogo)," Jurnal Pengembangan Teknologi Informasi dan Ilmu Komputer, vol. 2, no. 11, pp. 4654-4662, 2018. 